\begin{tabular}{|c|c|}
\hline $\begin{array}{l}\text { Aksaray University } \\
\text { Journal of Science and Engineering } \\
\text { e-ISSN: } 2587-1277 \\
\text { http://derginark.gov.tr/asuise }\end{array}$ & $\begin{array}{r}\text { Aksaray J. Sci. Eng., } 2019 \\
\text { Volume 3, Issue 1, pp.61-61 } \\
\text { doi: } \underline{\text { 10.29002/asujse.584470 }}\end{array}$ \\
\hline http://asujse.aksaray.edu.tr & Available online at DergiPark \\
\hline
\end{tabular}

\title{
CORRECTION to: Gaussian Modified Pell Sequence and Gaussian Modified Pell Polynomial Sequence [Aksaray J. Sci. Eng. 2(1) (2018) 63-72.]
}

Tulay Yagmur ${ }^{1,2, *}$, Nusret Karaaslan ${ }^{1}$

\author{
${ }^{1}$ Department of Mathematics, Aksaray University, Aksaray, Turkey \\ ${ }^{2}$ Program of Occupational Health and Safety, Aksaray University, Aksaray, Turkey
}

The authors of the paper [1] realized that since the concept of the modified Pell polynomials can be obtained as a special case of Horadam polynomials which introduced in [2], the paper [2] should be cited in introduction of [1]. For this reason, the sentence

"Additionally, the modified Pell polynomials are defined recursively by the relation $q_{n}(x)=$ $2 x q_{n-1}(x)+q_{n-2}(x)$ where $q_{0}(x)=1$ and $q_{1}(x)=x . "$

should be corrected as

"Additionally, as a special case of Horadam polynomials introduced by Horzum and Kocer in [2], the modified Pell polynomials are defined recursively by the relation $q_{n}(x)=2 x q_{n-1}(x)$ $+q_{n-2}(x)$ where $q_{0}(x)=1$ and $q_{1}(x)=x$."

\section{REFERENCES}

[1] T. Yagmur, N. Karaaslan, Gaussian Modified Pell Sequence and Gaussian Modified Pell Polynomial Sequence. Aksaray J. Sci. Eng. 2(1) (2018) 63-72.

[2] T. Horzum, E. Gokcen Kocer, On Some Properties of Horadam Polynomials. International Mathematical Forum 4(25) (2009) 1243-1252.

*Corresponding Author: Tulay Yagmur, tulayyagmurr@gmail.com; tulayyagmur@aksaray.edu.tr 